\title{
A novel crystallization-induced diastereomeric transformation based on a reversible carbon-sulfur bond formation. Application to the synthesis of a $\gamma$-secretase inhibitor
}

\author{
Antony J. Davies, ${ }^{, \dagger}$ Jeremy P. Scott, ${ }^{,},{ }^{\dagger}$ Brian C. Bishop, ${ }^{\dagger}$ Karel M. J. Brands, ${ }^{\dagger}$ Sarah E. \\ Brewer, ${ }^{\dagger}$ Jimmy O. DaSilva, ${ }^{\ddagger}$ Peter G. Dormer, ${ }^{\ddagger}$ Ulf-H. Dolling, ${ }^{\ddagger}$ Andrew D. Gibb, ${ }^{\dagger}$ \\ Deborah C. Hammond, ${ }^{\dagger}$ David R. Lieberman, ${ }^{\dagger}$ Michael Palucki ${ }^{\ddagger}$ and Joseph F. Payack ${ }^{\ddagger}$ \\ ${ }^{\dagger}$ Department of Process Research, Merck, Sharp \& Dohme Research Laboratories, \\ Hertford Road, Hoddesdon, Hertfordshire, EN11 9BU, United Kingdom and \\ ${ }^{\ddagger}$ Department of Process Research, Merck Research Laboratories, P.O. Box 2000, \\ Rahway, New Jersey 07065. \\ tony_davies2@merck.com; jeremy_scott@merck.com
}

\section{Supporting Information}

Table of Contents

1. General experimental

2. X-ray crystallographic data and ORTEP plots

3. ${ }^{1} \mathrm{H}$ and ${ }^{13} \mathrm{C}$ NMR spectra
Page

$S-1$

Trans-sulfide $\mathbf{8}$

$S-2$

Cis-sulfide 9

$S-3$

S-6 to $S-17$

\section{General experimental}

All reactions were carried out under a nitrogen atmosphere. All solvents and reagents were purchased from commercial sources and were used without further purification. ${ }^{1} \mathrm{H}$ and ${ }^{13} \mathrm{C}$ NMR chemical shifts are reported relative to residual proton solvent peaks. Melting points (open capillary) are uncorrected. All yields and w/t\% were determined by reverse phase HPLC assay using purified standards.

\section{X-ray crystallographic data and ORTEP plots}

Trans sulfide 8: The crystals were grown from isopropyl acetate. A single crystal was selected for single crystal x-ray data collection on a Bruker Smart Apex CCD system at low temperature $\left(-50^{\circ} \mathrm{C}\right)$. The crystal was colorless block with dimensions of $0.50 \mathrm{~mm}$ x $0.50 \mathrm{~mm}$ x $0.32 \mathrm{~mm}$. The unit cell was collected on 1 second scan rate and manual indexing gave the cell setting to be triclinic. The structure was solved in the triclinic P 1(bar) space group after a quadrant data collection using 1 second scan rate.

Table 1. Crystal data and structure refinement 


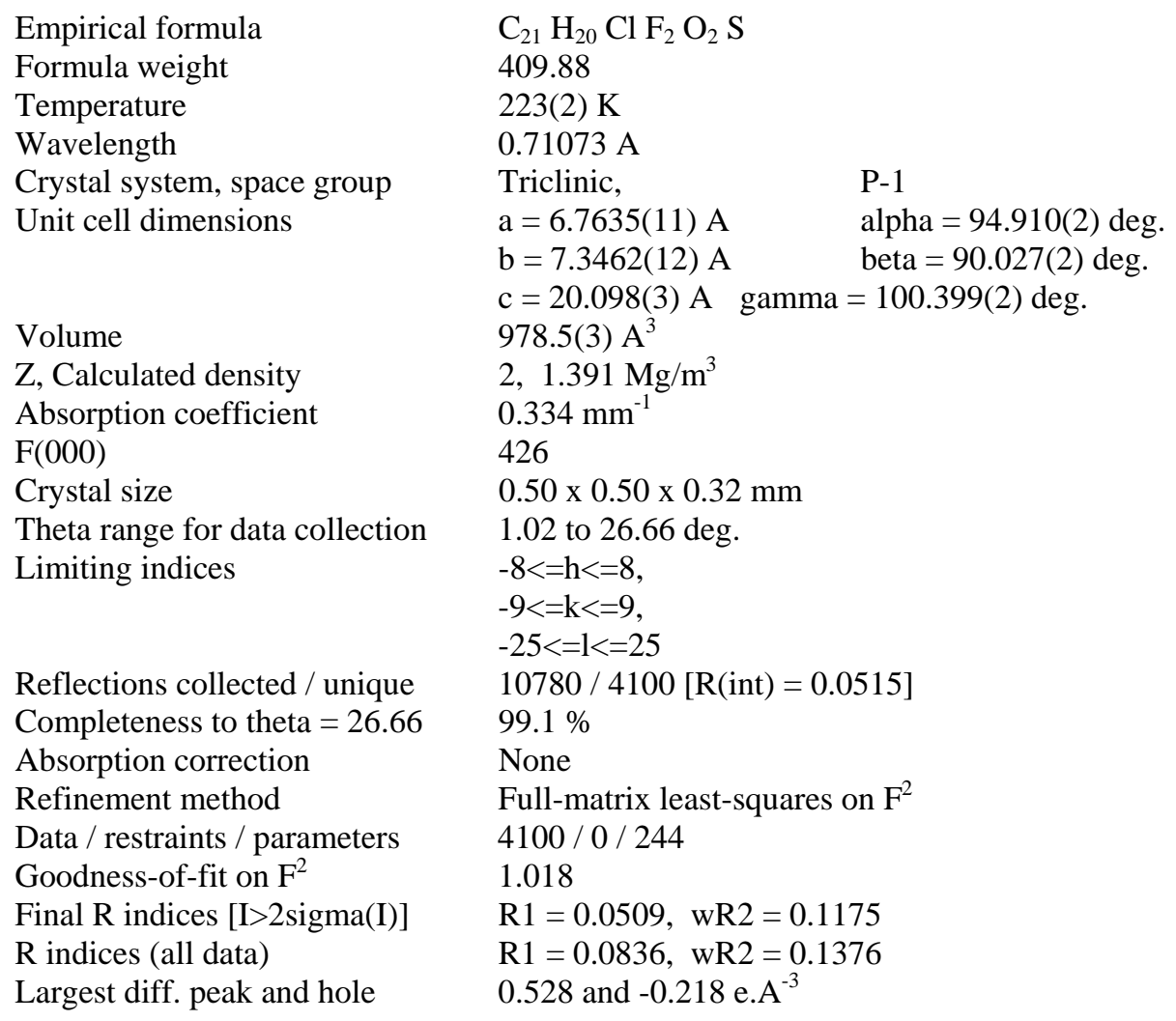




\section{Thermal Ellipsoid plot at $\mathbf{5 0 \%}$ probability for trans sulfide 8}

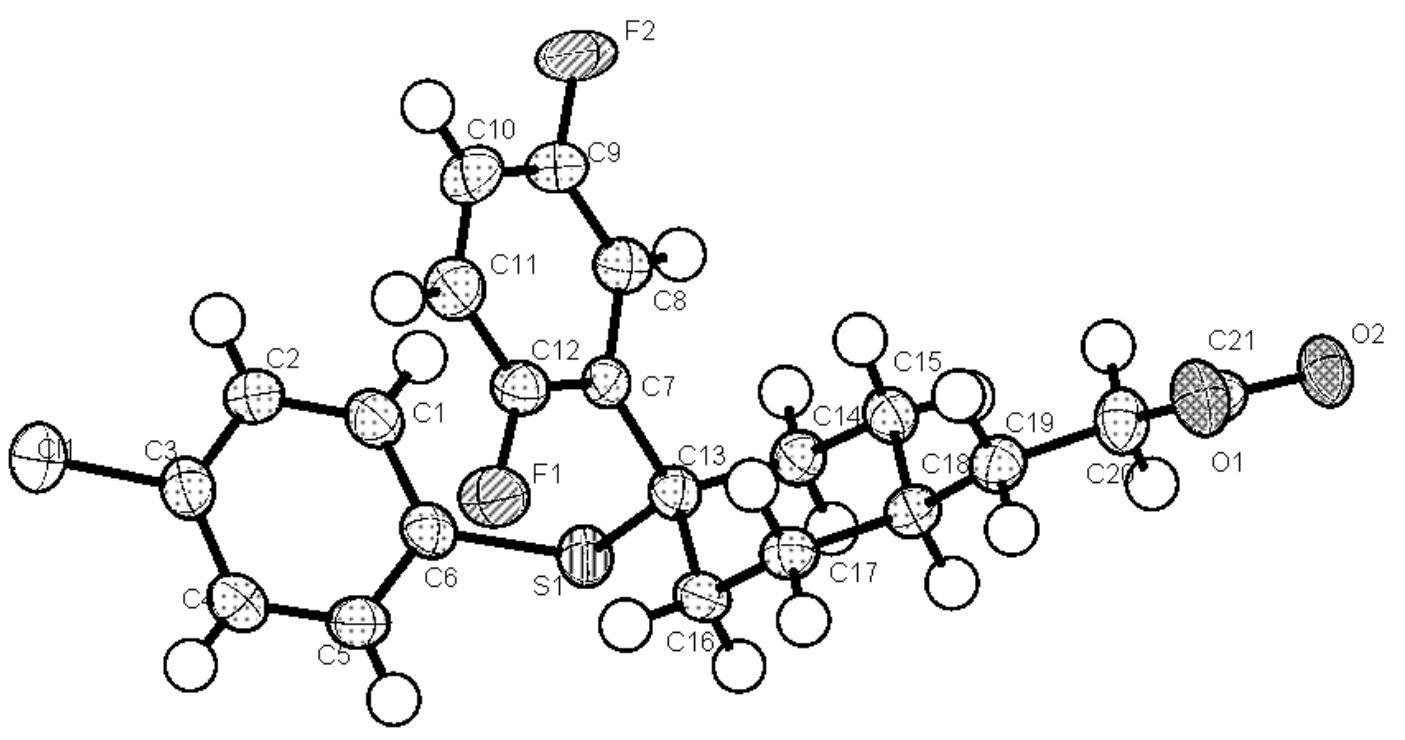

Cis sulfide 9: A single crystal was selected for single crystal $\mathrm{x}$-ray data collection on a Bruker Smart Apex system. The crystal was colorless plate with dimensions of $0.50 \mathrm{~mm} \times 0.420 \mathrm{~mm} \times 0.220 \mathrm{~mm}$. The unit cell was auto indexed using the matrix collected at a 1 second scan rate. The indexing gave the cell setting to be monoclinic. The structure was solved in the monoclinic C 2/c space group after a full quadrant of data collection using 1 second scan rate. Platon review of the structure suggests a solvent accessible void of 149.7 $\mathrm{Ang}^{3}$, correlating to $4007.0 \mathrm{Ang}^{3}$ [3.7\%] per unit cell volume.

\section{Table 2. Crystal data and structure refinement}

\author{
Empirical formula \\ Formula weight \\ Temperature \\ Wavelength \\ Crystal system, space group \\ Unit cell dimensions
}

Volume

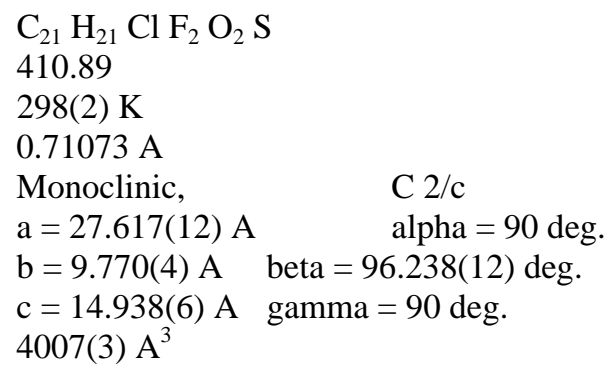


Z, Calculated density

Absorption coefficient

$\mathrm{F}(000)$

Crystal size

Theta range for data collection

Limiting indices

Reflections collected / unique

Completeness to theta $=26.42$

Absorption correction

Refinement method

Data / restraints / parameters

Goodness-of-fit on $\mathrm{F}^{2}$

Final R indices [I $>2 \operatorname{sigma}(\mathrm{I})$ ]

$\mathrm{R}$ indices (all data)

Largest diff. peak and hole
8, $1.362 \mathrm{Mg} / \mathrm{m}^{3}$

$0.326 \mathrm{~mm}^{-1}$

1712

$0.50 \times 0.42 \times 0.22 \mathrm{~mm}$

1.48 to $26.42 \mathrm{deg}$.

$-33<=\mathrm{h}<=34$,

$-12<=\mathrm{k}<=12$,

$-18<=\mathrm{l}<=18$

$20554 / 4069$ [R(int) $=0.0525]$

$98.5 \%$

None

Full-matrix least-squares on $\mathrm{F}^{2}$

4069 / 0 / 245

1.049

$\mathrm{R} 1=0.0530, \quad w R 2=0.1316$

$\mathrm{R} 1=0.0809, \quad \mathrm{wR} 2=0.1475$

0.499 and -0.438 e. $\mathrm{A}^{-3}$ 
Thermal Ellipsoid plot at $50 \%$ probability for cis sulfide 9

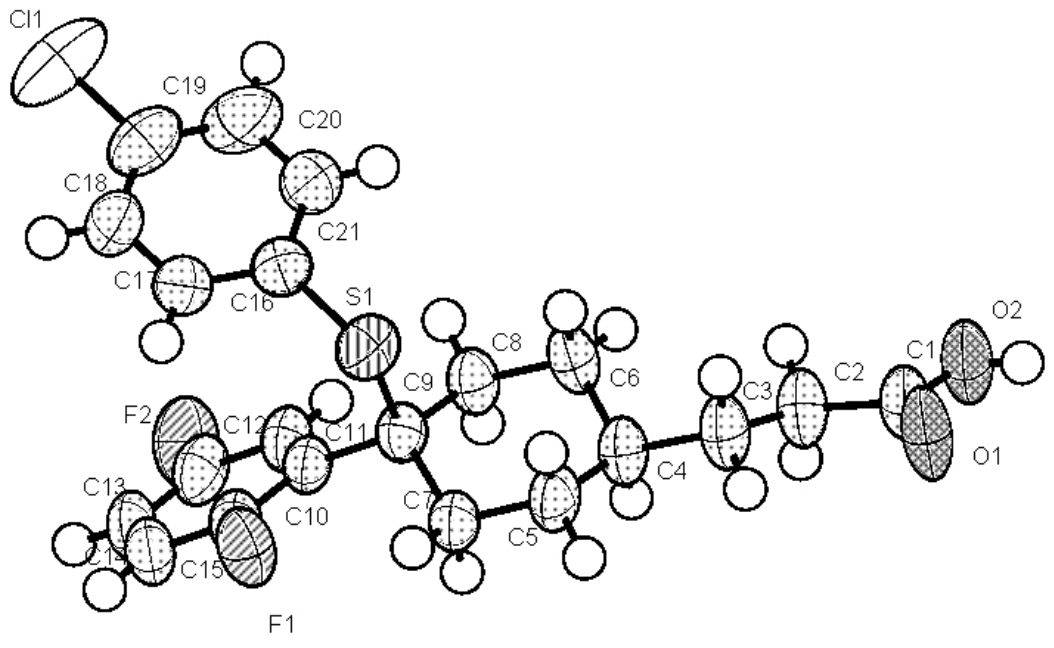




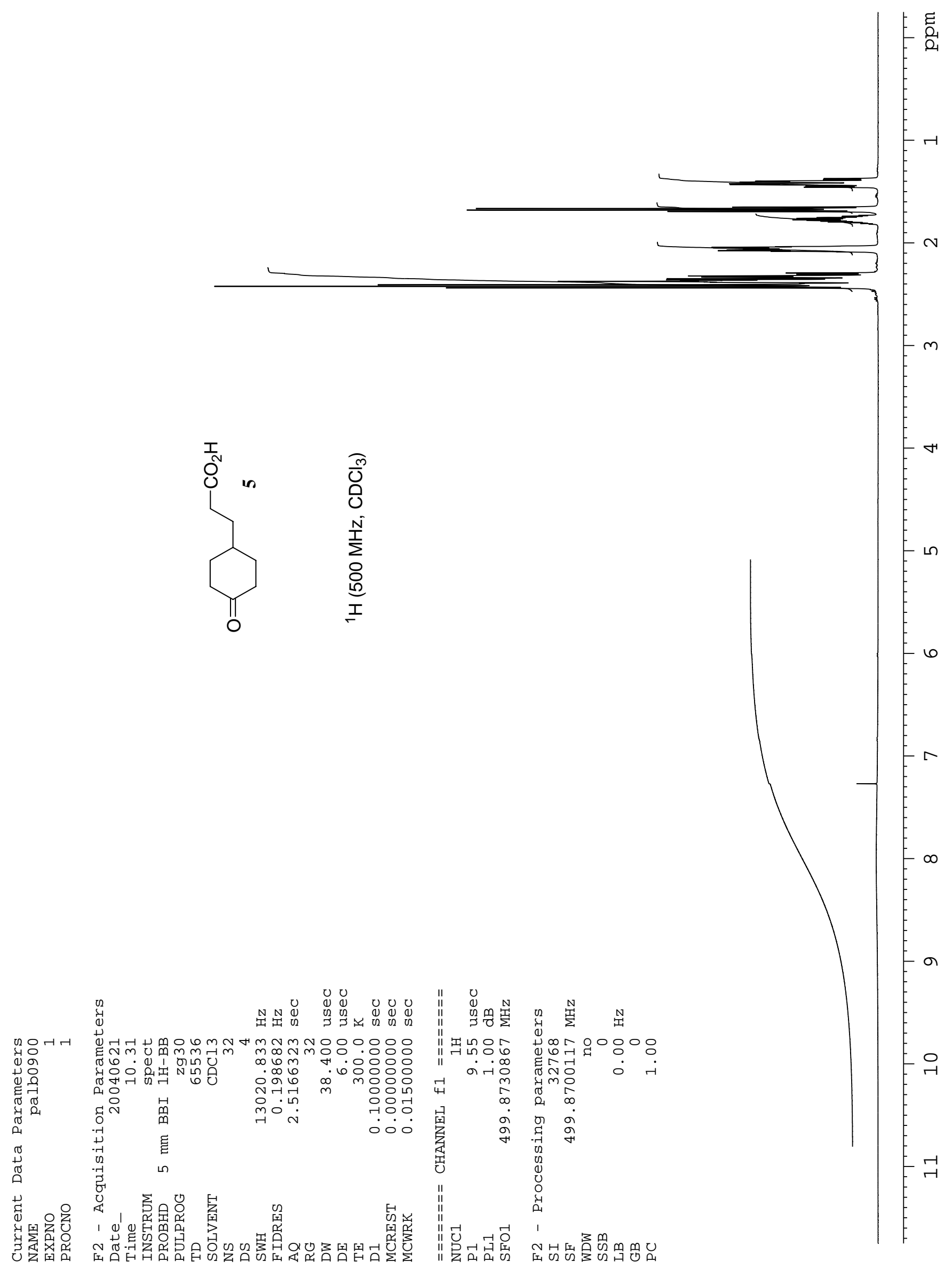




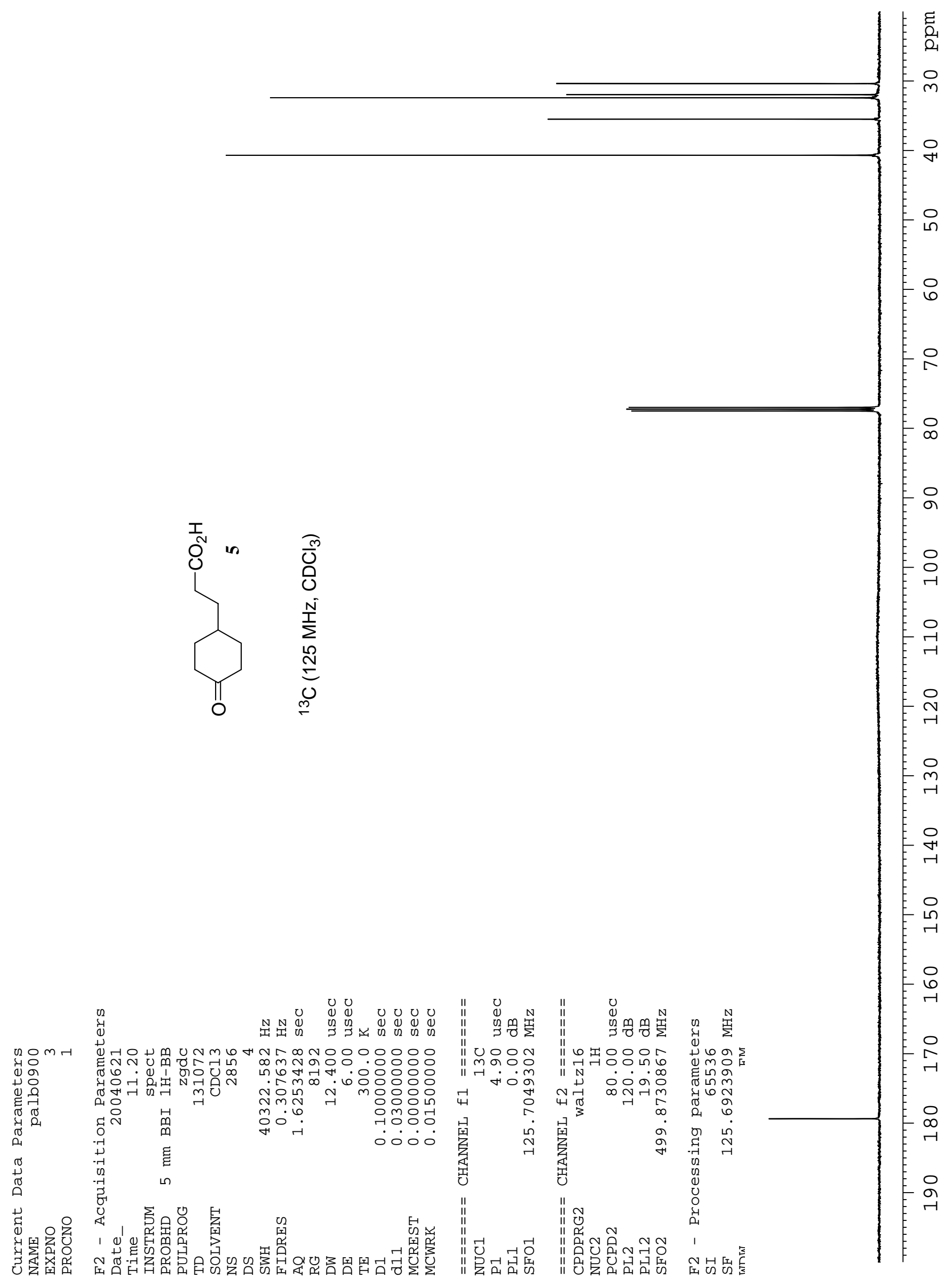




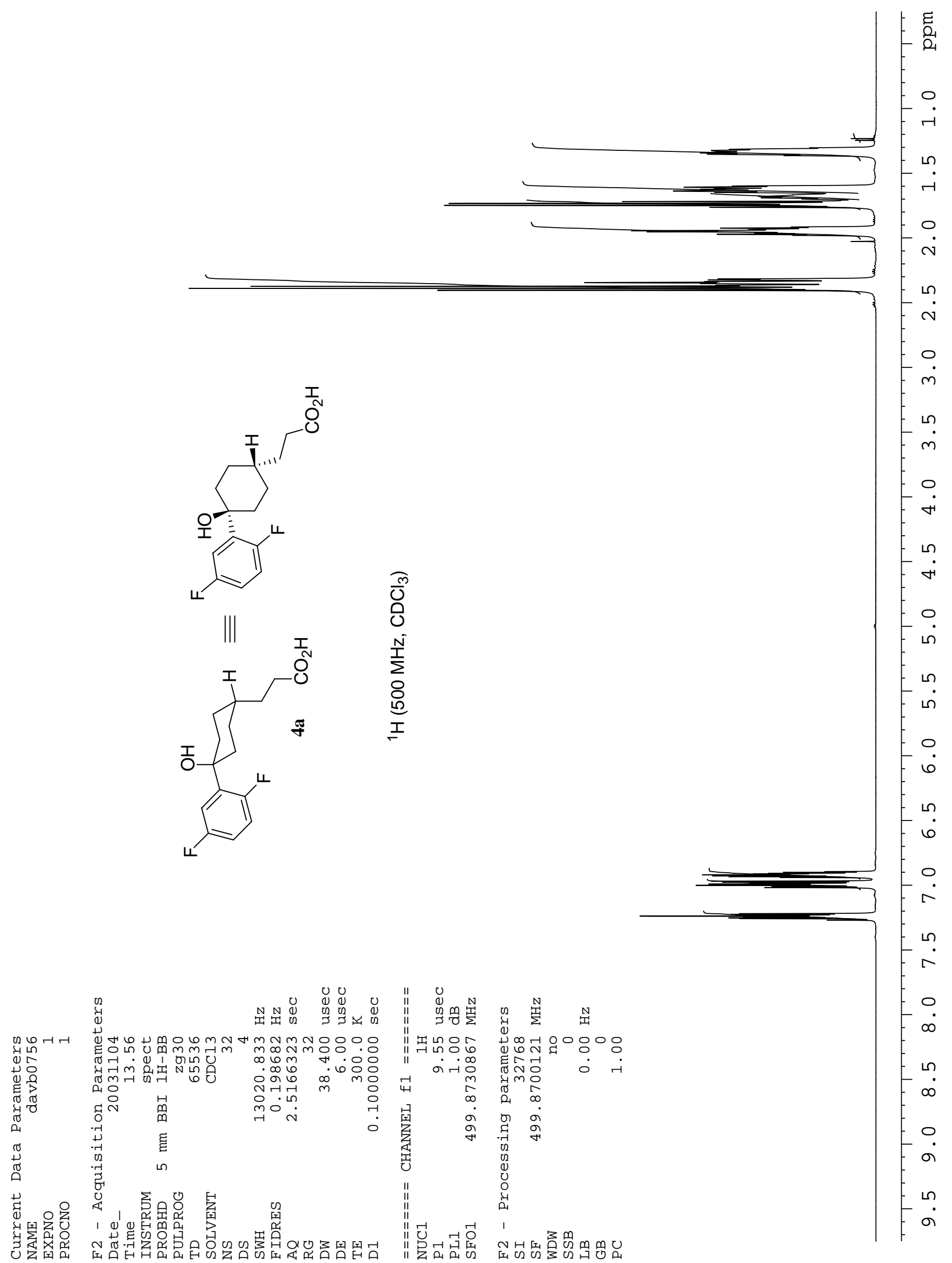




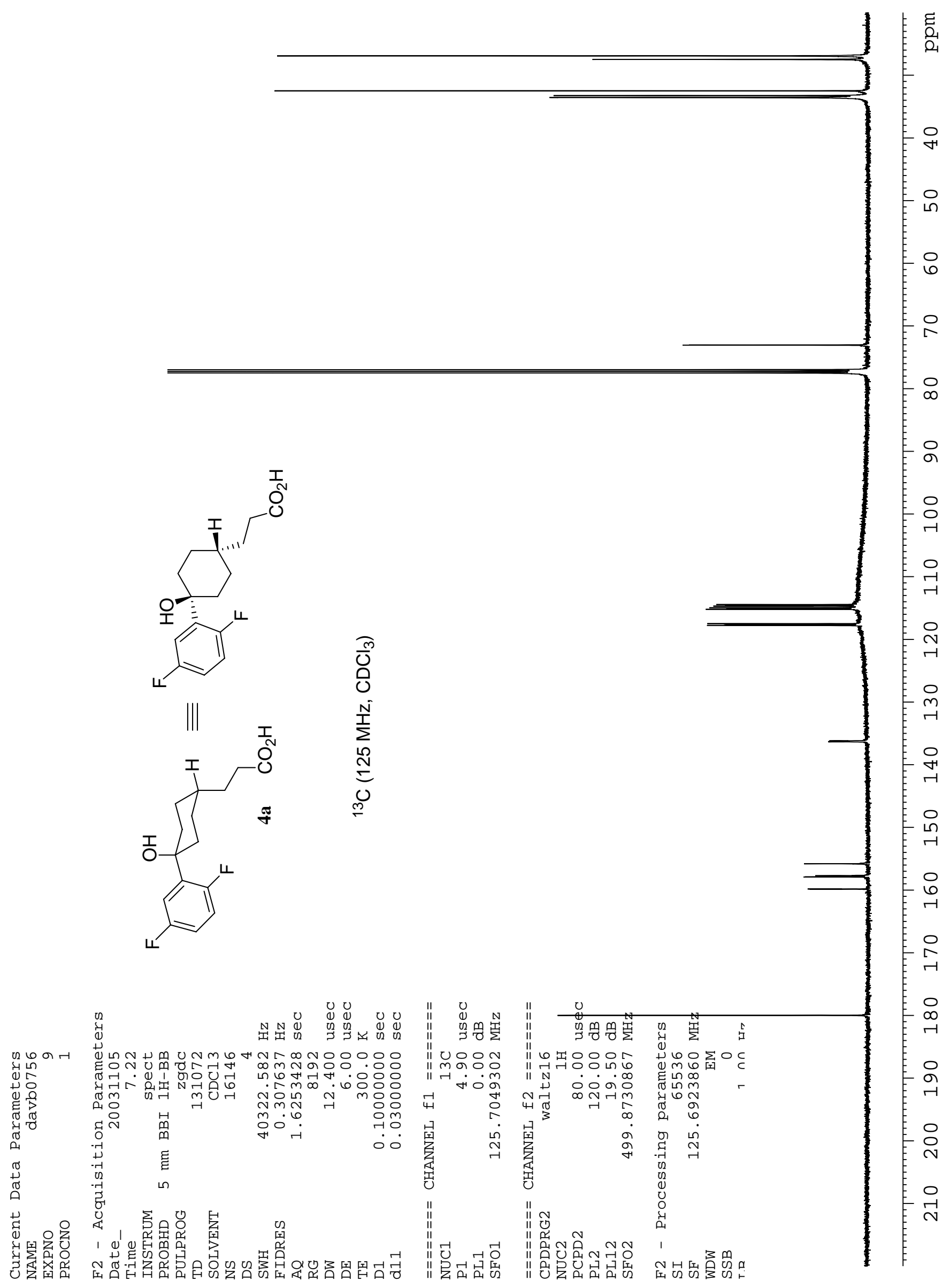




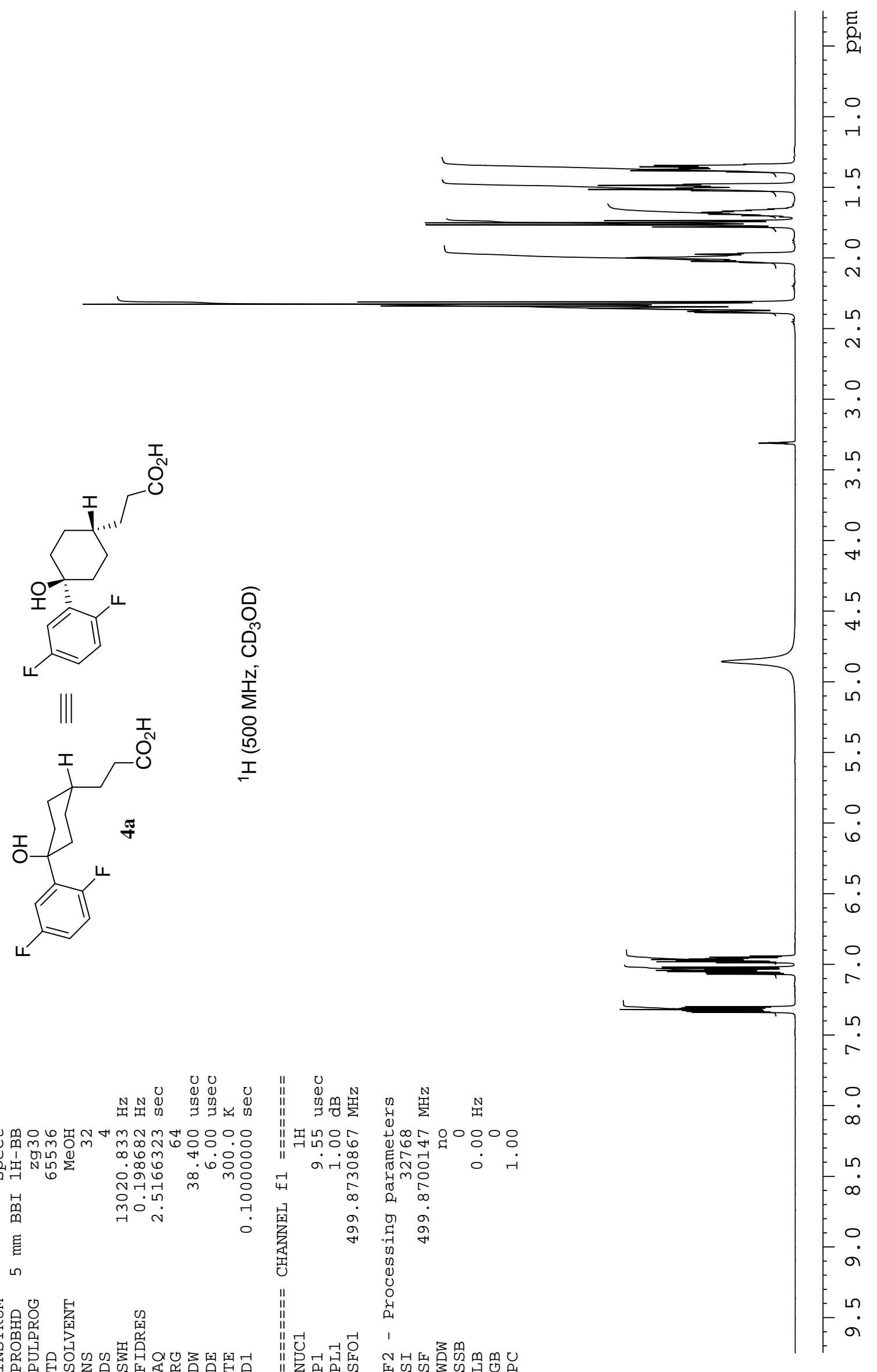




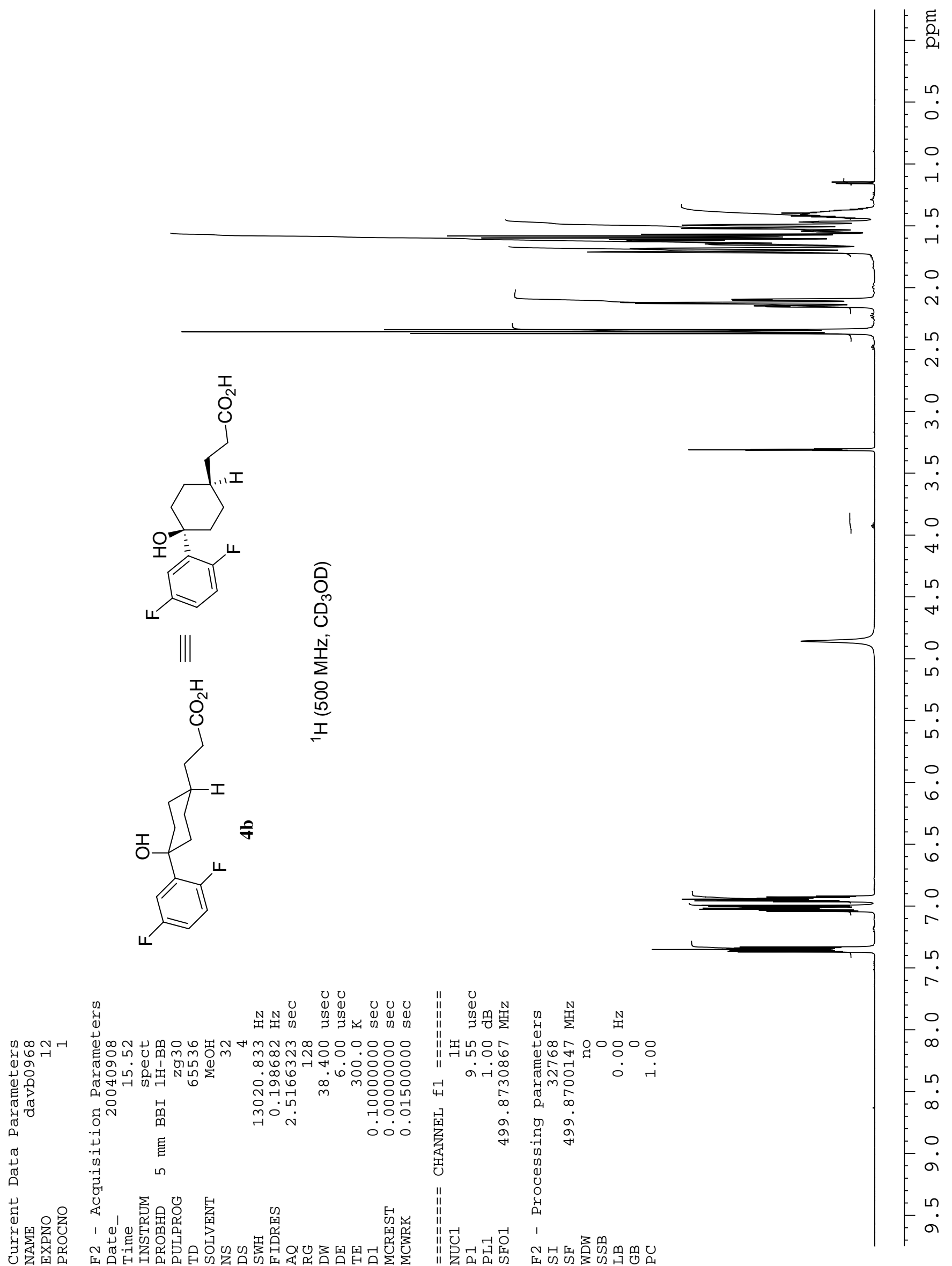




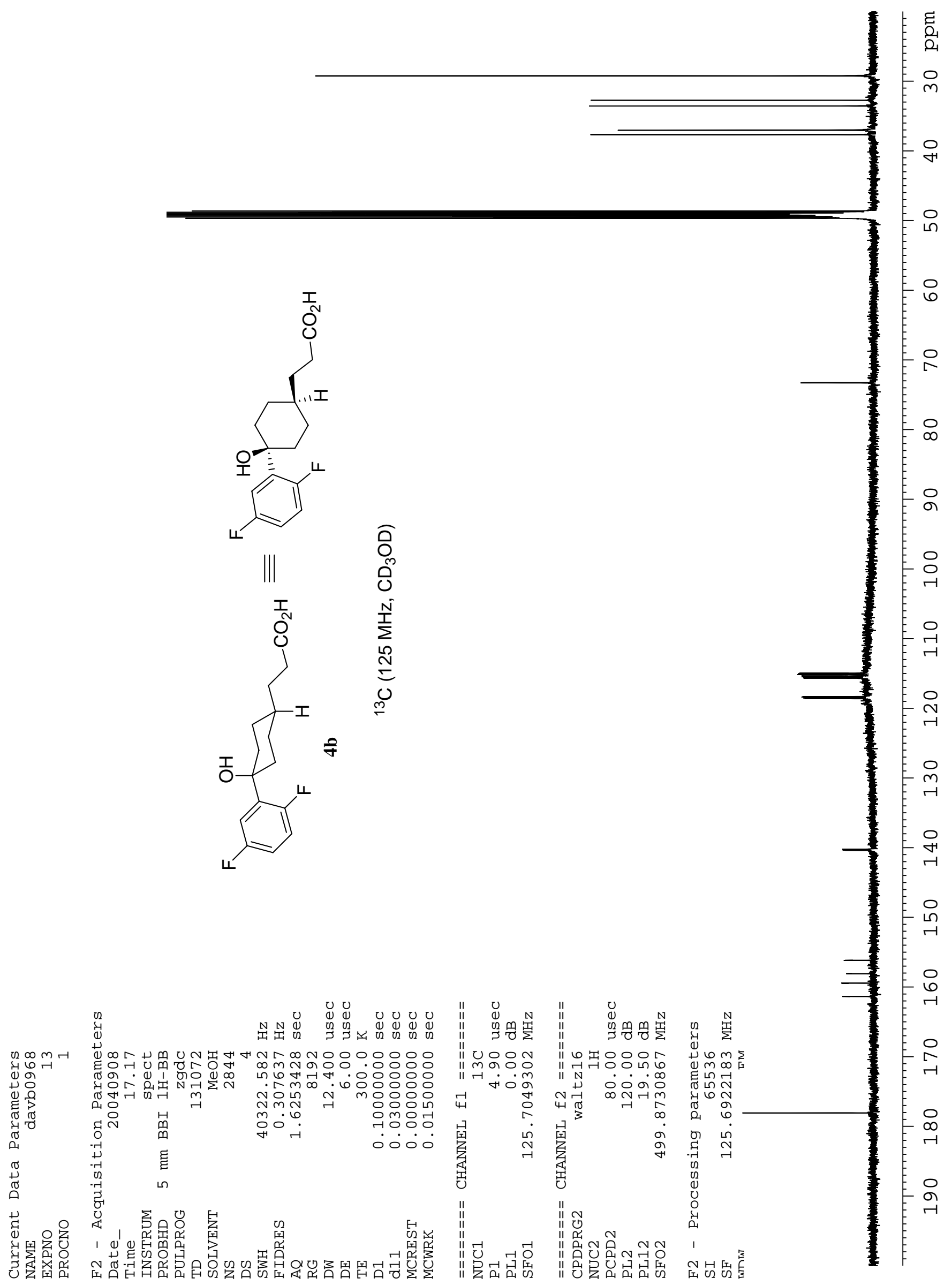



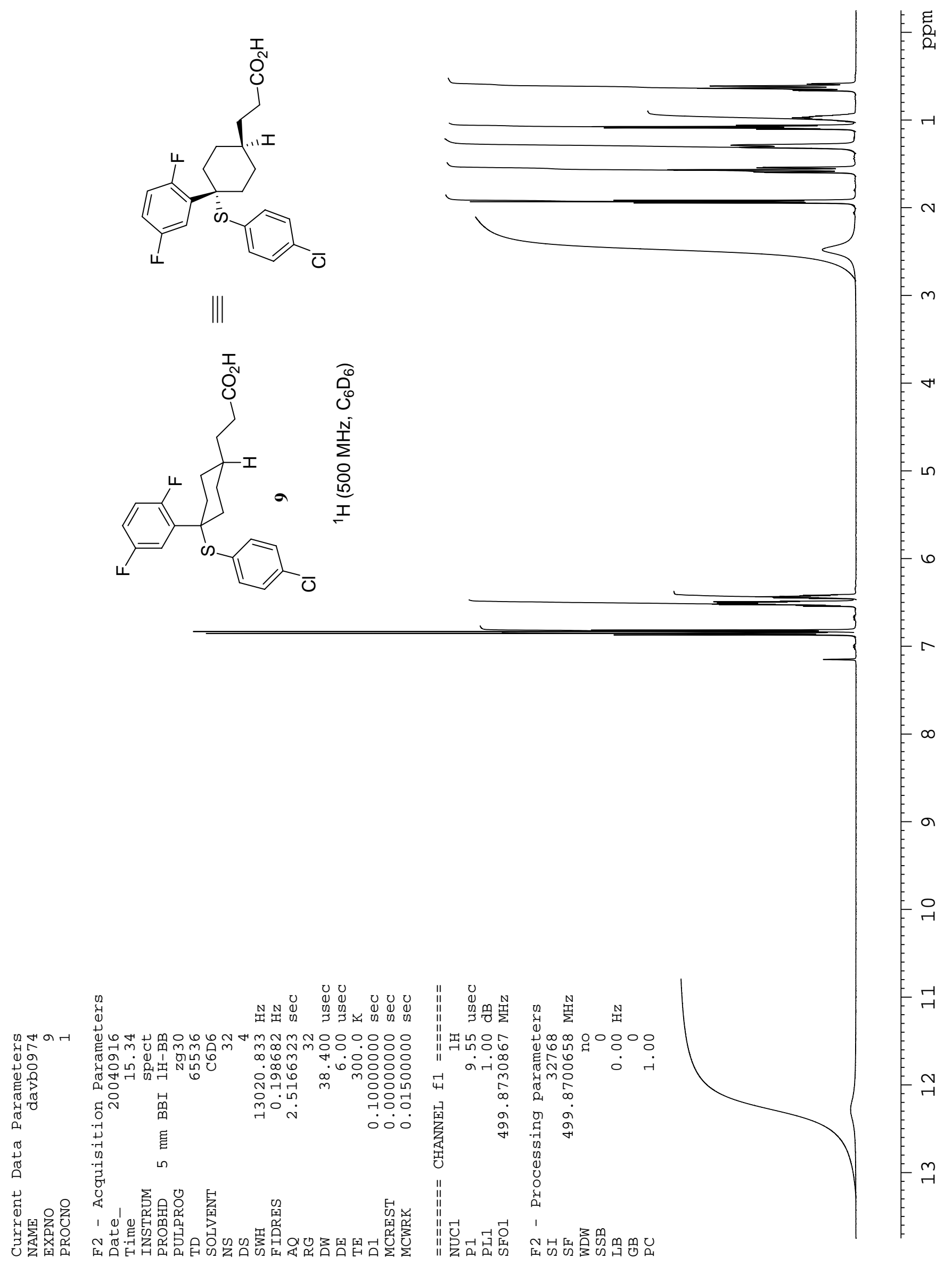

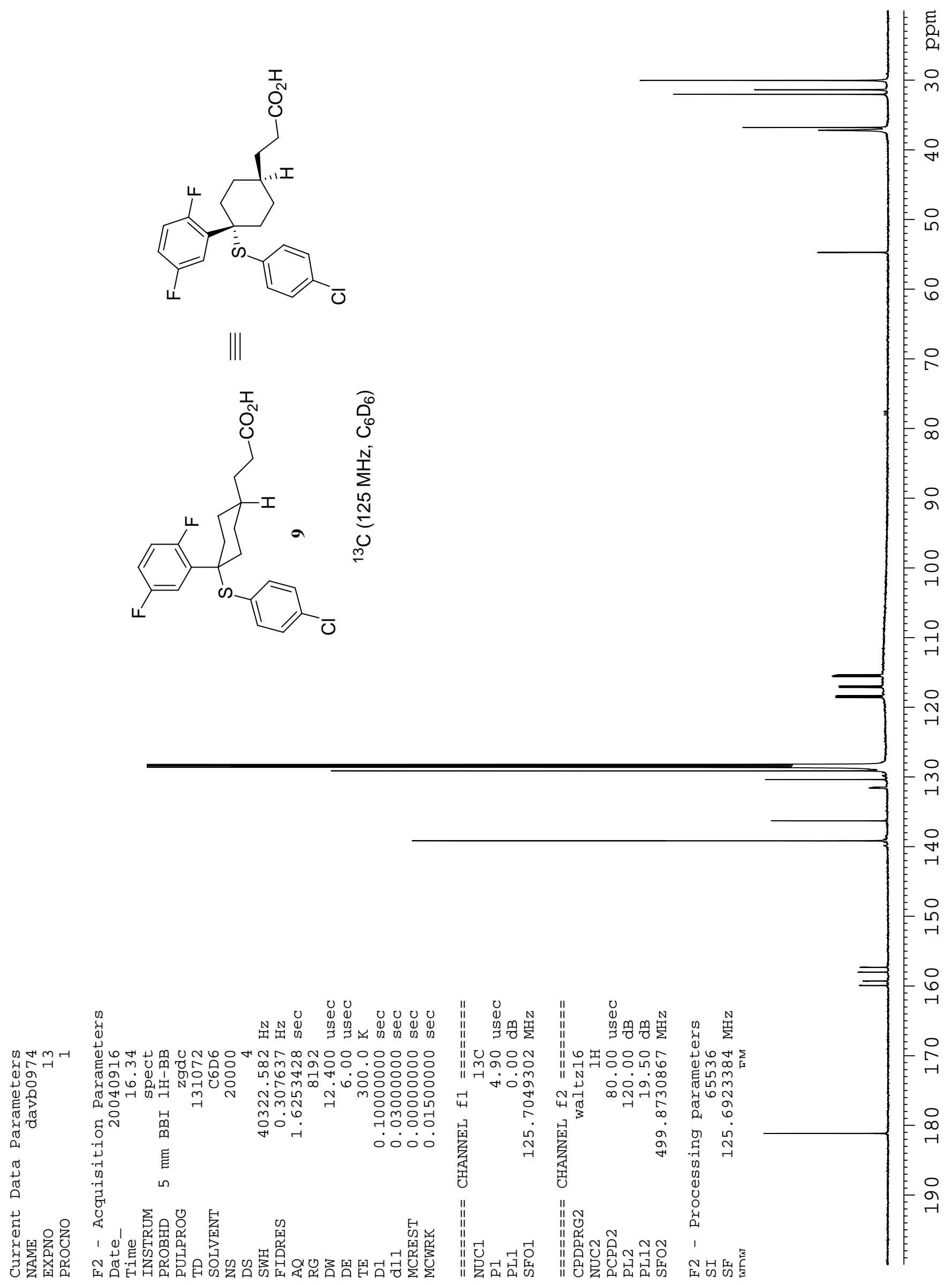

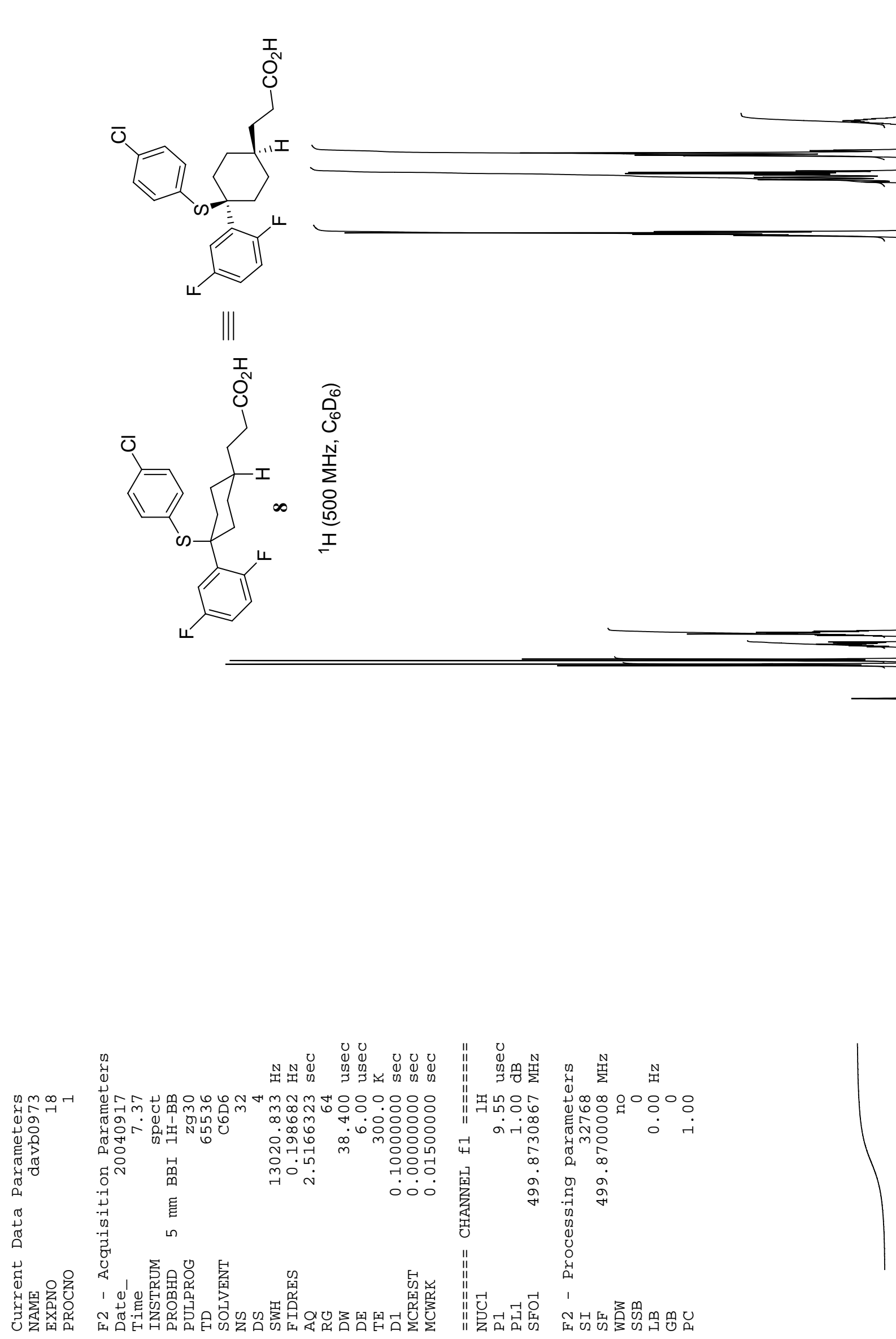


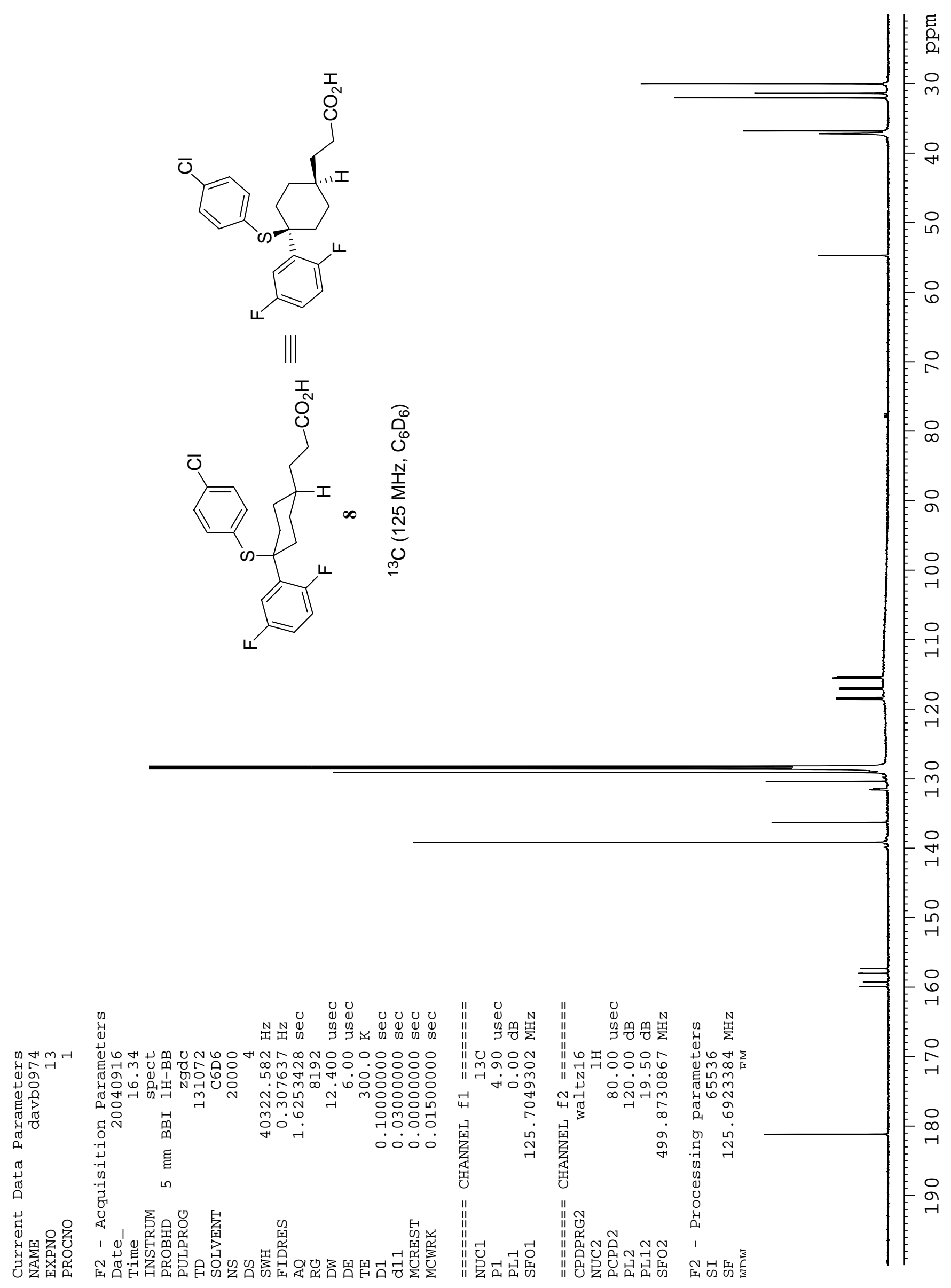



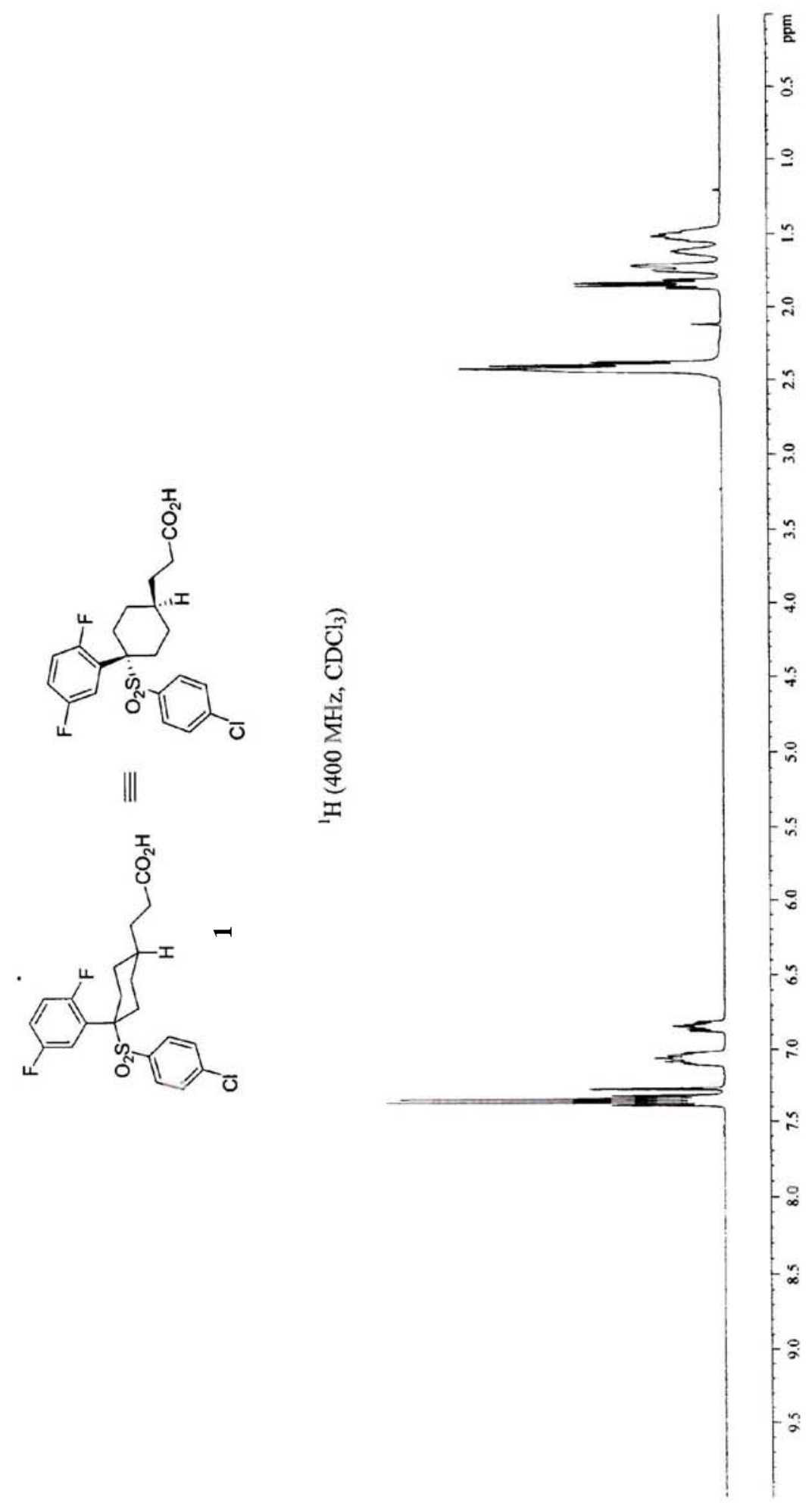